\title{
Competencias interculturales en estudiantes universitarios
}

\section{Intercultural competences in college students}

DOI: https://doi.org/10.32870/dse.v0i21.648

\section{Sabrina Nigra*}

\begin{abstract}
Resumen
En el presente trabajo se muestran los resultados de un estudio piloto realizado con estudiantes adscritos a un programa de aprendizaje de lenguas extranjeras, al mismo tiempo que están cursando la Licenciatura en Turismo en una universidad pública del occidente de México. El objetivo de este estudio fue explorar hasta qué punto los estudiantes están desarrollado o mejorando sus competencias interculturales a través del aprendizaje de un tercer idioma. El diseño metodológico que se utilizó en el estudio es mixto, y la perspectiva teórica que se tomó como referencia es el de la internacionalización en casa, que tiene entre sus objetivos el desarrollo de las competencias interculturales.
\end{abstract}

Palabras claves: Comunicación intercultural - Educación global - Educación internacional.

\begin{abstract}
This paper shows the results of a pilot study conducted with students who are learning in a foreign language program while they are pursuing a degree in Tourism at a public university in western Mexico. The objective of this study was to explore to what extent students are developing or improving their intercultural competences through the learning of a third language. The methodological design that was used in the study is mixed and the theoretical perspective that was taken as a reference is internationalization at home, one of whose objectives is the development of intercultural competences.
\end{abstract}

Keywords: Intercultural communication - Global Education - International Education.

\section{Descripción de la problemática}

El fenómeno de la globalización tiene efectos en todos los sectores: educativo, económico, cultural y político; es un hecho que cada vez más personas en todo el mundo están conectadas a través de las nuevas tecnologías. En el siglo XXI todos se comunican con personas de otras

* Maestra en didáctica del italiano como lengua extranjera por la Universidad de Venecia. Principales temas de investigación: internacionalización de la educación superior, interculturalidad y aprendizaje de lenguas extranjeras. Universidad de Guadalajara. México. sabrinanigra@ cucea.udg.mx 
culturas (Fantini, 2009) y todos necesitan tener las habilidades para interactuar de una forma positiva con personas de otra cultura.

La globalización demanda a los ciudadanos de hoy y de mañana tener competencias globales, interculturales e internacionales, lo que implica que las Instituciones de Educación Superior den una respuesta adecuada en la formación de los ciudadanos del futuro con mentalidad mundial. No obstante, hay muchos indicios que confirman el hecho de que no lo están logrando, como reportan varios estudios (Gregersen-Hermans, 2014; Jones, 2014).

Respecto del tema, la Organización para la Cooperación y el Desarrollo Económicos (OCDE), en 2018 publicó las nuevas directrices para el examen PISA, que apuntan a la evaluación de las competencias globales.

La OCDE define la competencia global como un conjunto de capacidades multidimensionales. Los individuos competentes globalmente pueden analizar cuestiones globales, locales e interculturales, entendiendo y apreciando las diferentes perspectivas y visiones del mundo, interactuando de forma exitosa y respetuosa con otras personas, realizando acciones de una forma responsable y sustentable (OECD, 2018: 4).

Con esta definición, la OCDE pone el acento en la competencia intercultural de los jóvenes para favorecer interacciones respetuosas entre individuos en un mundo global donde las sociedades, con sus diferencias, están interconectadas.

Por otra parte, la UNESCO (2013), en su documento "Cuadro conceptual y operativo para las competencias interculturales", se compromete a apoyar en la difusión de las competencias interculturales proponiendo una serie de directrices para las instituciones educativas. En la Declaración Universal de los Derechos humanos (UNESCO, 1948), el párrafo 2 del artículo 26 ya sostenía que la educación debe tener como objetivo el desarrollo total del ser humano, promoviendo el respeto de los derechos humanos y de las libertades fundamentales. En ese sentido, las competencias interculturales promueven la coexistencia armoniosa entre las culturas, según los principios que esta organización internacional expone en los dos documentos mencionados.

En las encuestas a empleadores de los últimos años se encontró que, aunque los egresados tienen las capacidades técnicas, no poseen las competencias trasversales necesarias para el mundo del trabajo como: resolución de problemas (problem solving), trabajo en equipo, comunicación efectiva y flexibilidad (Jones, 2014). El mismo autor afirma que hay estudios que demuestran que la exposición de los estudiantes a diferentes perspectivas culturales fomenta la competencia intercultural, como parte de las competencias trasversales.

Uno de los retos de la la educación superior en el contexto de la globalización es la creación de un currículo internacional e intercultural que enfrente los cambios de una sociedad líquida caracterizada por el cambio constante, citando al sociólogo Zygmunt Bauman (2000).

Diálo@os sobre Educación año 11 | número 21 | julio-diciembre 2020 | ISSN 2007-2171 
Por lo tanto, en el presente estudio se realiza un análisis de las políticas educativas mexicanas contenidas en documentos oficiales, para identificar cómo se aborda la internacionalización y las competencias interculturales en la Educación Superior.

En el análisis del Plan Nacional de Desarrollo (2013a) del sexenio pasado (2012-2018), se evidencia la intención de fortalecer las políticas de internacionalización en el sector educativo, y el concepto de interculturalidad aparece en relación con la integración de las comunidades indígenas en la educación.

Con respecto al Plan Sectorial de Educación (2013b), se remarca como objetivo: fortalecer la educación internacional con acuerdos de cooperación que favorezcan la movilidad, mientras que, en cuanto a la interculturalidad, se cita la intención de fortalecer una educación intercultural y bilingüe, es decir, se quiere involucrar más a las comunidades indígenas y se pretende impulsar una educación bilingüe (español-inglés). En realidad, México ya es un país intercultural y multilingüe gracias a las numerosas comunidades indígenas que existen en el país, lo que falta es sumar las comunidades indígenas a los retos educativos con más compromiso. Adicionalmente, la promoción de la educación bilingüe no es acorde a la realidad de un país que es multilingüe.

Como el estudio se llevó a cabo en la Universidad de Guadalajara (UdeG), universidad pública del occidente de México y la segunda institución educativa estatal en el país, es pertinente mencionar que en el Plan Estatal de Desarrollo de Jalisco (2014) no se menciona la palabra interculturalidad y la internacionalización es citada únicamente en relación con la intención de aumentar la movilidad estudiantil y académica.

Por otro lado, el Plan de Desarrollo Institucional 2014-2030 (2014) de la UdeG, en su eje de internacionalización, objetivo número 12, considera las competencias interculturales y globales; manifiesta la necesidad de integrar una dimensión intercultural y el aprendizaje de idiomas extranjeros en todos los programas educativos de la red universitaria, además de que en la malla curricular de la Licenciatura en Turismo se considera obligatorio el aprendizaje de más de una lengua extranjera.

Por esta razón, el presente trabajo también tiene como objetivo explorar hasta qué punto los estudiantes de dicha carrera están desarrollado o mejorando sus competencias interculturales a través del aprendizaje de un tercer idioma, como lo sostienen diferentes autores (Byram, 1997; Fantini, 2000).

La perspectiva teórica que guía el estudio es la posible relación positiva entre la interculturalidad y el aprendizaje de las lenguas extranjeras en el marco contextual de la internacionalización en casa, línea que incluye el análisis de las estrategias y actividades que la universidad lleva a cabo con el objetivo de desarrollar las competencias interculturales que, de otra forma, únicamente podría adquirir una pequeña parte de los estudiantes y el profesorado que participan en programas de movilidad. 
Desafortunadamente, como señala Jones (2014), la relación entre los resultados de la internacionalización y la empleabilidad no ha sido muy estudiada. Por este motivo, es primordial realizar más estudios como este, sobre la internacionalización en casa y las competencias interculturales en el contexto mexicano; y también realizar estudios que aborden las estrategias de internacionalización en casa y el perfil internacional de los estudiantes.

Finalmente, preparar a los estudiantes para los retos globales debería ser un resultado al cual aspira la internacionalización, es decir, un egresado que sea ciudadano global, con conocimientos específicos y multidisciplinarios, así como una serie de competencias trasversales que incluyen también la interculturalidad (Deardorff, 2011).

En la investigación se ulilizó un diseño metodológico mixto, que incluye la aplicación de una encuesta y la realización de un grupo focal. Los resultados informan sobre la condición de las competencias interculturales de los estudiantes en el estudio de una tercera lengua y pueden sirvir para abrir camino a otros trabajos sobre las actividades de internacionalización en casa y la interculturalidad en los programas de aprendizaje de lenguas extranjeras universitarios.

La estructura del trabajo es la siguiente: en el primer apartado se describen las perspectivas teóricas que sirvieron de sustento al estudio; en el segundo se presenta una descripción de la metodología utilizada; en el tercero se muestran los hallazgos más significativos del estudio; y finalmente, se exponen unas reflexiones y recomendaciones.

\section{Perspectivas conceptuales y teóricas}

Existe abundante producción científica sobre las competencias interculturales, el aprendizaje de las lenguas extranjeras y la internacionalización en casa. A continuación, se presentan los resultados de la revisión realizada.

\section{La internacionalización, la internacionalización en casa y la globalización}

En primer lugar, es necesario especificar que los conceptos de globalización e internacionalización son nociones que se asemejan, sin embargo, no son sinónimos (Alsina Valdés, Capote y Ampudia Rueda, 2009).

La globalización se refiere "a las tendencias económicas, tecnológicas y científicas que afectan directamente la educación superior y que son inevitables en el mundo contemporáneo". (Altbach, et al., 2009: 23, traducción propia), mientras que la internacionalización se refiere a las "políticas y programas emprendidos por los gobiernos, los sistemas académicos, las instituciones, e incluso por los departamentos que están involucrados en la globalización" (Altbach, et al., 2009: 23, traducción propia). Por consiguiente, la internacionalización de la educación superior se interpreta como una respuesta a la globalización, que es un elemento insoslayable de nuestra sociedad contemporánea (Albach y Knight, 2006).

Diólopos

sobre Educación año 11 | número 21 | julio-diciembre 2020 | ISSN 2007-2171 
En los últimos 25 años, la dimensión de la internacionalidad se ha convertido en un tema central para los gobiernos, la educación superior y las organizaciones extragubernamentales. La internacionalización de la educación superior es un área vasta de investigación que engloba diferentes categorías: política, económica, social, cultural y académica, y de la cual existen múltiples definiciones (De Wit y Jones, 2014).

Para el presente trabajo se eligió la definición de internacionalización de Jane Knight, por considerarse la más adecuada ya que incluye la dimensión cultural, que textualmente dice: "la internacionalización de la educación superior es el proceso de integrar la dimensión internacional, intercultural o global en el objetivo, funciones o resultados de la educación superior" (Knight, 2008: 21, traducción propia). En la definición se observa que contiene todas las estrategias de internacionalización, incluso la internacionalización en casa, las competencias interculturales, y no solamente las de movilidad.

Sin embargo, es fundamental mencionar que, dado que el estudio tiene como propósito investigar la posible relación positiva entre la interculturalidad y el aprendizaje de las lenguas extranjeras, se considera una estrategia especial de internacionalización, llamada internacionalización en casa. Este concepto, propiamente, será tomado como eje principal dentro de la internacionalización.

La línea de internacionalización en casa, efectivamente, es la que incluye el análisis de las estrategias y las actividades que la universidad lleva a cabo en el interior de la misma institución, con el objetivo de desarrollar las competencias interculturales, que de otra forma solo podría adquirir una pequeña parte de los estudiantes y el profesorado que participan en programas de movilidad.

El concepto de internacionalización en casa (internationalization at home - IAH) fue desarrollado por Nilsson en 1999, junto con otro sinónimo: internacionalización interna (internal internationalization). El concepto introducido por Nillson (1999) estaba estrictamente relacionado con la internacionalización del currículo y con la integración de los estudiantes internacionales.

Posteriormente, Khight (2008) propone una definición más amplia del término, que incluye: el aprendizaje de lenguas y culturas extranjeras, las actividades de extensión y extracurriculares, la internacionalización del currículo, el proceso de enseñanza y aprendizaje, la movilidad virtual y los enlaces con comunidades culturales y étnicas.

Una de las definiciones más recientes de internacionalización en casa es la de Beelen y Jones (2015), quienes afirman que: "La internacionalización en casa es la integración intencional de la dimensión internacional e intercultural en currículo formal e informal para todos los estudiantes en ambientes de aprendizaje en el campus" (2015: 69). En esta última definición, la dimensión internacional e intercultural está integrada en todos los ejes sustantivos del desarrollo de las actividades universitarias, para que todos los estudiantes posean habilidades interculturales e internacionales, como resultado de la internacionalización en casa de toda la institución universitaria. 
En efecto, todos los procesos de internacionalización deberían tener como objetivo abarcar $100 \%$ de la población estudiantil, a través de una internacionalización integral que apunte al aumento de la empleabilidad de los egresados, y no centrarse únicamente en una pequeña parte de los estudiantes, impulsando solo la movilidad, que es la estrategia más conocida e implementada. Agnew (2014), quien presenta unas directrices y modelos prácticos para implementar la internacionalización a fin de que los estudiantes tengan las competencias interculturales que se requieren hoy en día, menciona también que solo $2 \%$ de la población mundial estudiantil participó en 2007 en algún programa de movilidad y que únicamente $9.4 \%$ de los estudiantes estadunidenses estudiaron en el extranjero entre 2012 y 2013 (Agnew, 2014).

De igual manera, al analizar los indicadores del Plan de Desarrollo Institucional de la UdeG en materia de internacionalización, la situación no es diferente. La institución reporta que en 2013 solo 0.6\% del estudiantado participó en programas de movilidad; para 2019 aspira llegar a $3 \%$, y para 2030 y a $10 \%$ de su matrícula (UdeG, 2014: 85 ).

Asimismo, examinando los datos del Informe de Actividades (2018) de la Coordinación General de Cooperación e Internacionalización de la misma universidad, se aprecia un incremento significativo en movilidad con respecto al año anterior, correspondiente a 39.72\% (UdeG, 2019: 21). Sin embargo, los 2,081 estudiantes totales de movilidad saliente equivalen a menos de $1 \%$ de sus alumnos $(404,229)$, de acuerdo con los datos reportados en los Numeralia institucionales (UdeG, 2018).

Adicionalmente, hay tendencias mundiales que señalan la disminución de la movilidad estudiantil, como en Australia y Estados Unidos, pronosticada desde 2004, debido a múltiples factores como, por ejemplo: la seguridad nacional, el aumento del terrorismo, los altos costos de los estudios, la expansión del e-learning y de la movilidad virtual (Albach y Knight, 2006).

\section{Las competencias interculturales}

Por lo que concierne el concepto de competencia intercultural $(\mathrm{Cl})$, hay varios autores, entre ellos Darla Deardorff (2011), que aceptan que no existe un consenso en cuanto a su definición y terminología disciplinar.

Fantini (2009: 196) enuncia algunos de los términos con los cuales algunos investigadores se refieren a la $\mathrm{Cl}$ desde diversas disciplinas, como por ejemplo: global competence, multiculturalism, cross-cultural adaptation, intercultural sensitivity, cultural intelligence, international communication, transcultural communication, cross-cultural awareness y global citizenship. Sin embargo, en el presente estudio se tomarán como referencia los modelos de Cl de Byram (1997), Bennett (2004), Fantini (2000) y Deardorff (2004).

Byram (1997) define la competencia comunicativa intercultural (Intercultural communicative competence - ICC) como un conjunto de cinco saberes separados donde la comunicación en lengua extranjera adquiere relevancia: el savoir (el conocimiento de la otra cultura y de la pro-

Diálo@os sobre Educación 
pia), el savoir comprendre (el saber entender e interpretar), el savoir apprendre (el saber aprender, interactuar y querer descubrir la otra cultura), el savoir etre (el saber ser, tener las actitudes de curiosidad, respeto y apertura hacia el otro) y por último, el savoir s'engager (el ser consciente de la otra cultura y de la propia).

En cambio, Bennett (Hammer, Bennett y Wiseman, 2003) crea un modelo de desarrollo de la sensibilidad intercultural, que Ilama Developmental Model of Intercultural Sensitivity (DMIS) e identifica la competencia intercultural como una evolución desde el etnocentrismo al etnorrelativismo. A continuación, se presenta una figura que explica el desarrollo por fases de la $\mathrm{Cl}$ de acuerdo con el autor.

Figura 1 Developmental Model of Intercultural Sensitivity (DIMS)

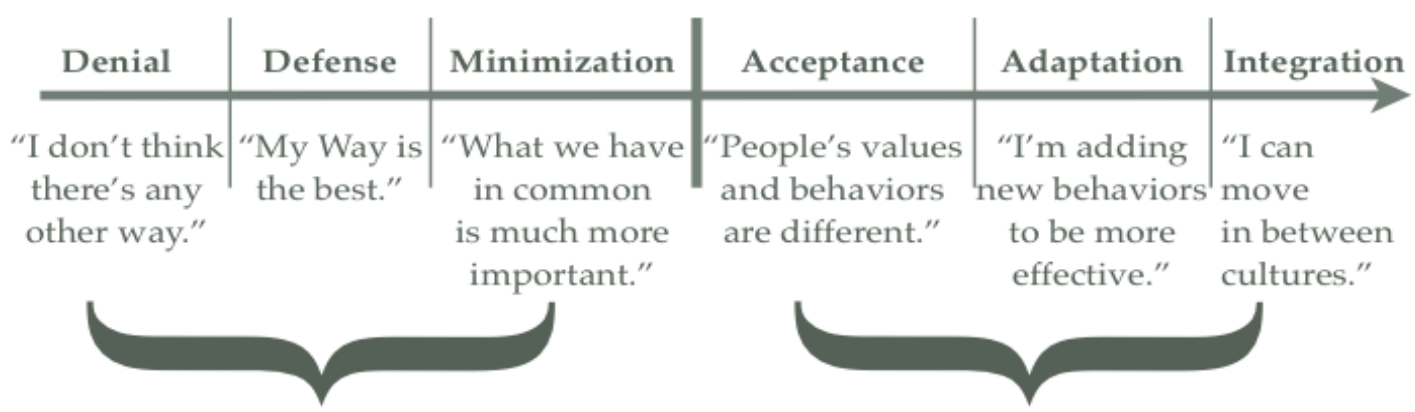

Ethnocentric Stages

Ethnorelative Stages

El desarrollo de la competencia intercultural va desde la Negación de las diferencias entre culturas, pasando por la Defensa, que es el punto donde el individuo cree que su cultura es la única correcta y luego, por la Minimización. Cuando el individuo se encuentra en la Aceptación, su cultura es percibida como una de las posibles visiones del mundo entre las otras culturas. En la fase de Adaptación el individuo se comporta apropiadamente, según las reglas de la otra cultura; y en la última fase, la Integración, el individuo es capaz de moverse entre diferentes culturas (Bennett, 2004).

Alvino E. Fantini (2009) retoma la idea central de Byram acerca de la centralidad de la comunicación en lengua extranjera, y afirma que una buena competencia en otra lengua constituye gran parte de la competencia intercultural, pero también se necesitan otros componentes. Fantini (2000), que desarrolla el paradigma 'KASA' (por sus siglas en inglés: Knowledge, Attitude, Skills y Awareness), define la competencia intercultural como el conjunto de habilidades necesarias para hablar de forma efectiva y apropiada en una lengua extranjera con una persona que habla otra lengua y es de otra cultura.

Las dimensiones que Fantini identifica como parte de la competencia intercultural son: el conocimiento, las habilidades, las actitudes y la conciencia de la competencia (Fantini, 2000). De 
todas, la conciencia es la más relevante porque representa el grado de reflexión e introspección entre las dos lenguas y culturas. La conciencia de la otra cultura no se puede olvidar como el conocimiento declarativo. A continuación, se presenta gráficamente el modelo desarrollado por Fantini.

Figura 2. Paradigma Kasa (Knowledge, attitude, skills y awareness)

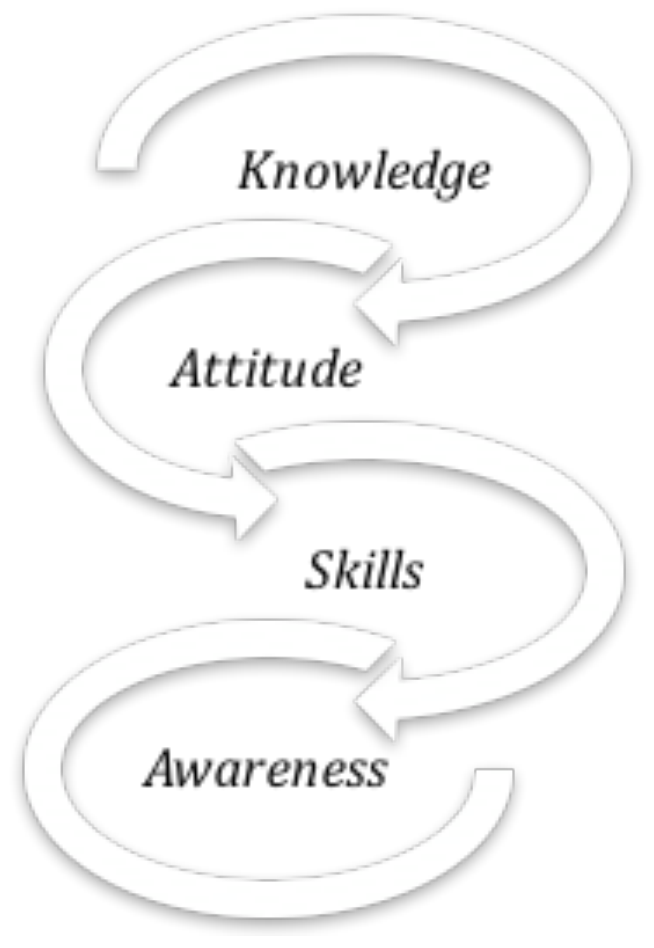

La competencia en una segunda lengua, como parte del conocimiento, nos lleva a la confrontación de cómo percibimos, conceptualizamos, expresamos e interactuamos en nuestra primera lengua, y utilizamos estrategias alternativas de comunicación apropiadas a la segunda lengua. El proceso de aprendizaje de una lengua extranjera nos ayuda a trascender y cambiar nuestra forma habitual de ver al mundo. La falta de competencia en una segunda lengua, aunque sea a un nivel básico, nos impide pensar sobre el mundo y actuamos con un solo sistema. La falta de aprendizaje de una segunda lengua, entonces, nos impide tener un contacto intercultural valioso, como también las percepciones que derivan de él (Fantini, 2000: 200, traducción propia).

La competencia lingüística es el componente con el cual interpretamos el mundo y nuestra realidad. 
Por último, se presenta el modelo de competencia intercultural desarrollado por Deardorff (2004), que sugiere una definición más general donde la $\mathrm{Cl}$ es un proceso en constante construcción, como se muestra a continuación:

Figura 3. El modelo Deardorff

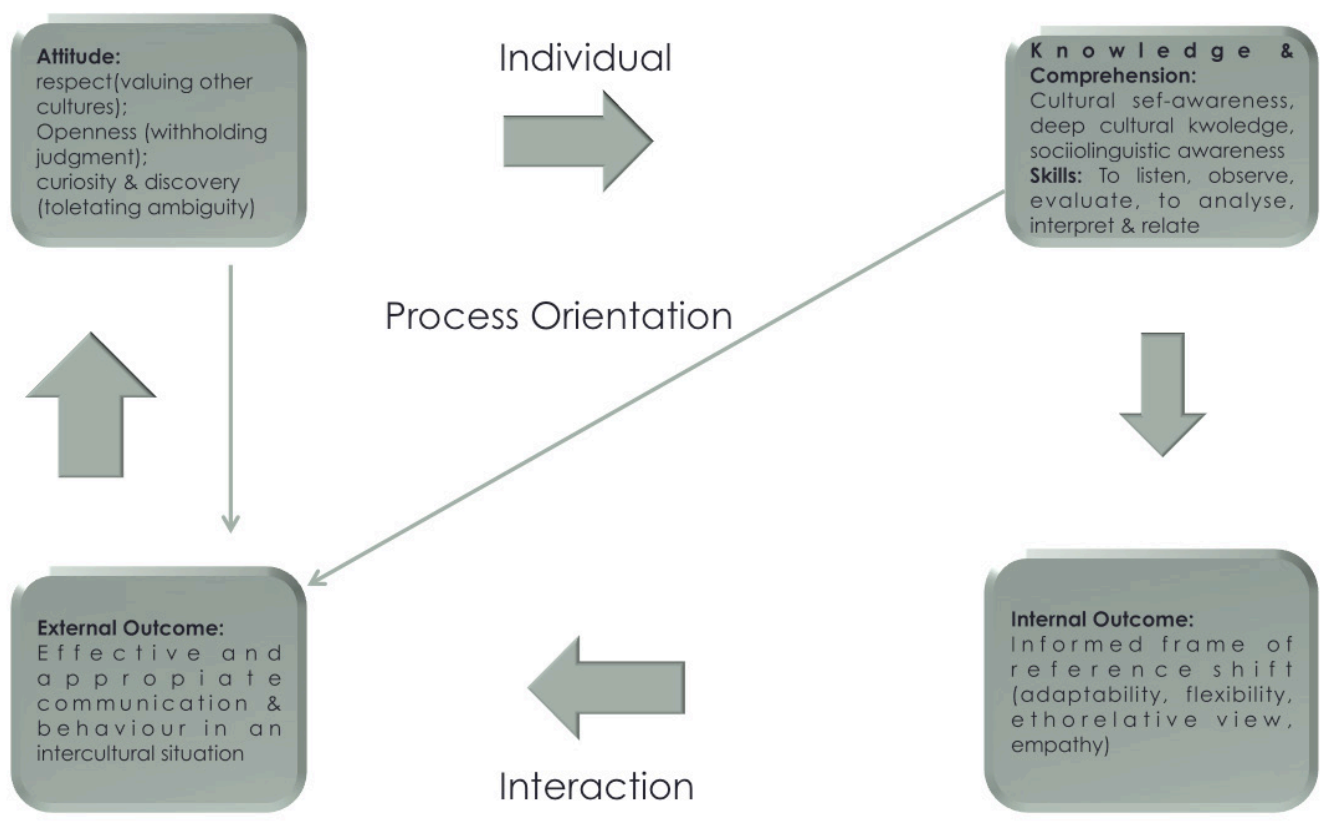

Según el modelo Deardorff (2011) la competencia intercultural es formada por la actitud, el conocimiento y la comprensión; los resultados externos e internos al individuo. Es central que el individuo desarrolle pensamiento crítico para evaluar sus conocimientos, como también tener una actitud de respeto y curiosidad hacia las otras culturas. Según la autora, el individuo competente interculturalmente debería tener la habilidad de ver las cosas desde el otro punto de vista, que es aún más importante que el conocimiento declarativo (Deardorff, 2011).

\section{Evaluar las competencias interculturales}

La evaluación de las competencias culturales es compleja porque, en primer lugar, no existe un consenso en la literatura sobre su definición, como se destacó en el apartado anterior.

Deardorff (2011) sugiere que la forma más adecuada para evaluar la competencia intercultural es empezar por su definición, después se identifican sus componentes, y luego se determinan objetivos mesurables según el contexto de referencia. La misma autora comenta que los instrumentos más efectivos para la medición de la competencia son un conjunto de métodos 
cualitativos y cuantitativos, porque con métodos solo cuantitativos o cualitativos no se logra una evaluación eficaz.

A continuación, se presenta una tabla que contiene varios métodos de evaluación de competencia intercultural, elaborado con base en la revisión documental realizada para la elaboración de los instrumentos del presente estudio (Fantini, 2005; Deardorff, 2011; Griffith et al., 2016).

Tabla I. Tipologías de evaluación

\begin{tabular}{|c|c|}
\hline Tipo evidencia & Producto \\
\hline Directa & Contratos de aprendizaje \\
\hline Directa & Portafolios digitales o portafolios de estudiantes \\
\hline Directa & Reportes \\
\hline Directa & Reflexiones críticas \\
\hline Directa & Eesempeño \\
\hline Indirecta & Entrevistas \\
\hline Indirecta & Grupo focal, workshop \\
\hline Indirecta & Análisis de diarios \\
\hline Indirecta &
\end{tabular}

Lo que se pudo inferir del análisis de las fuentes documentales es que los instrumentos de medición indirecta de tipo cuantitativo abundan, y siguen siendo los más utilizados en la actualidad, con respecto a los instrumentos de medición indirecta cualitativos y los instrumentos de evaluación indirecta que son escasos (Griffith et al., 2016).

\section{El diseño metodológico}

\section{Selección de la población y de la muestra}

El principal objetivo de este estudio es analizar las competencias interculturales de los estudiantes de la carrera de Turismo de la UdeG. La idea central que guía la investigación es que los alumnos, a través del estudio de más de una lengua y cultura extranjera, adquieren algunas de las dimensiones de la competencia intercultural, como se afirma en los trabajos analizados en la revisión de la literatura.

En cuanto a la selección, primero se escogió la población y en segundo lugar, la muestra con los criterios que se mencionan a continuación.

En el estudio se utilizó una muestra intencional: fueron elegidos los estudiantes que cursan el $4^{\circ}$ nivel de su segunda lengua extranjera. La población objetivo era de 210 estudiantes y la muestra fue de 106, equivalente a 50 por ciento. 
La población es constituida por los estudiantes de la carrera de Turismo de la UdeG, del Centro de Ciencias Económico Administrativas que, según los datos del Informe de Matrícula de 2017-2018, son 1,684 estudiantes: 430 hombres y 1,254 mujeres (UdeG, 2018). Los estudiantes de dicha carrera, según su plan de estudio en el Área de Formación Básica Particular Selectiva, tienen que estudiar dos lenguas extranjeras. La segunda lengua extranjera obligatoria es el inglés (4 niveles / 8 semestres) y la tercera lengua extranjera (4 niveles / 8 semestres) puede elegirse entre las lenguas ofrecidas en el PALE, que actualmente son: español, italiano, francés, alemán y japonés. Es forzoso aprobar los cuatro niveles de estudio de la segunda lengua extranjera para poder empezar el estudio de la tercera.

La población objetivo son los estudiantes de la carrera de Turismo que cursan el nivel 4 de la tercera lengua extranjera. En el semestre 2018A el número de estudiantes con esta característica fue de 210, según los datos reportados por el PALE. La muestra del estudio fue intencional, dado que se supone que los estudiantes tienen sólidas competencias interculturales con base en el modelo elaborado por Fantini (2009), descrito en el apartado anterior.

Para la creación de los instrumentos del estudio, en particular para la formulación de las preguntas, se tomó como referencia la encuesta elaborada por Alvino Fantini (2005) para evaluar las competencias interculturales de unos voluntarios de diferentes nacionalidades europeas que se encontraban en una misión en Ecuador en 2005. Se eligió este instrumento porque incluye de manera específica una sección de las competencias interculturales obtenida a través del uso de la lengua extranjera.

\section{Técnicas y análisis de los datos}

Respecto a la metodología empleada para la evaluación de las competencias interculturales, fue mixta; se utilizaron técnicas de recolección de datos cualitativos y cuantitativos, retomando la idea desarrollada por Deardorff (2006), según la cual, para evaluar las competencias interculturales es adecuado combinar las dos metodologías.

El orden metodológico de la investigación fue explicativo secuencial y se dividió en dos fases (Creswell, 2014). La fase I corresponde a un enfoque cuantitativo (descriptivo) y la fase II, a un enfoque cualitativo (interpretativo). Los resultados cuantitativos fueron interpretados con la estadística descriptiva $y$, después, para explicar e interpretar a profundidad dichos resultados, se recolectaron datos cualitativos.

En la fase I (cuantitativa) se elaboró una encuesta y se aplicó a la muestra descrita, de la cual se obtuvieron 106 respuestas. En la fase II (cualitativa) se utilizó la técnica del grupo focal en una parte limitada de la muestra, para conocer más a fondo las experiencias y los pensamientos de las participantes en la encuesta y enriquecer con el relato directo sus respuestas de la fase I.

El grupo focal fue estructurado combinando un grupo con elementos heterogéneos y homogéneos de seis personas. La sesión fue grabada, tuvo una duración de dos horas, se pre- 
sentaron los resultados de la encuesta con gráficos y se realizaron preguntas elaboradas por el moderador para facilitar el intercambio de opiniones.

\section{Elaboración de la encuesta}

A través de la revisión de la literatura de los últimos diez años acerca de las competencias interculturales, se seleccionaron dos modelos teóricos de referencia para la presente investigación: el paradigma KASA, de Fantini (2009), y el de Deardorff (2004).

Se eligió el modelo de Fantini por la importancia que otorga al conocimiento de la lengua y cultura extranjera como medio de comunicación (competencia comunicativa intercultural). También se eligió el modelo Deardorff (2004), por la relevancia que otorga a la idea de competencia intercultural como proceso, y a los resultados internos que determinan al individuo, como la conciencia de su adquisición.

Sin embargo, como la idea central que guía el trabajo es que los estudiantes, a través del estudio de dos lenguas y culturas extranjeras, adquieren algunas de las dimensiones de la competencia intercultural, se dedicaron algunas preguntas específicamente a este tema.

Respecto a la formulación de las preguntas, se tomó como referencia el cuestionario que Fantini (2005) elaboró para su proyecto de investigación con la Federation of The Experiment in International Living (FEIL), donde evaluó las competencias interculturales de los voluntarios británicos y suizos en un programa de servicio en Ecuador.

El cuestionario elaborado para el proyecto FEIL tenía 60 reactivos; en cambio, la encuesta elaborada para el presente estudio tiene 15 preguntas, con escala Likert de frecuencia y de experiencia. Se dividió en cuatro partes, que corresponden a las cuatro dimensiones de la competencia intercultural que se pretendía evaluar. Se decidió a propósito no utilizar en la encuesta el término competencia intercultural.

A continuación, se describe la estructura del cuestionario:

PARTE I. La actitud. [3 preguntas] El estudiante demuestra respeto (pregunta 1), abertura (pregunta 2) y curiosidad hacia el otro (pregunta 3).

PARTE II. Las habilidades internas [4 preguntas] El estudiante es adaptable y paciente (pregunta 4);

flexible y tolerante (pregunta 5); etnorrelativo, suspende el juicio (pregunta 6); y por último, es empático (pregunta 7).

PARTE III. Las habilidades externas [3 preguntas]. El estudiante se comporta apropiadamente comunicando en una situación intercultural (preguntas 8, 9 y 10).

PARTE IV. El conocimiento comunicativo intercultural [5 preguntas]. El estudiante tiene conocimiento profundo de su cultura (pregunta 11), conocimiento profundo de otras culturas (preguntas 12 y 13) y conocimiento sociolingüístico (lengua y comunicación) en las lenguas extranjeras estudiadas (preguntas 14 y 15).

\section{Diólo@os}




\section{Los resultados}

En la encuesta, del total de 106 personas, 69.8\% son mujeres y 30.2\% hombres. La edad de los encuestados está en un rango que va de los 20 hasta los 28 años y $33 \%$ tiene 22 años. $34 \%$ se encuentra estudiando el octavo semestre y $27.4 \%$ el noveno.

Los encuestados declararon que su lengua materna es el español y en cuanto a la tercera lengua que estudian: $44.3 \%$ estudia francés, $35.8 \%$ italiano, solamente $13.2 \%$ estudia alemán y $6.7 \%$ japonés.

En relación con las respuestas que los estudiantes dieron a las preguntas de la 1 a la 6, sobre la actitud y las habilidades internas interculturales, observando los gráficos a continuación (figuras 4, 5, 6, 7, 8, 9), se infiere que la gran mayoría de los estudiantes tiene un alto grado de respeto hacia otras culturas, no juzga a las personas extranjeras con base en estereotipos; son curiosos y abiertos cuando interactúan con los extranjeros. Además, son personas flexibles, etnorrelativas y empáticas, según el modelo Deardorff (2004).

Figura 4. Comportamiento atento

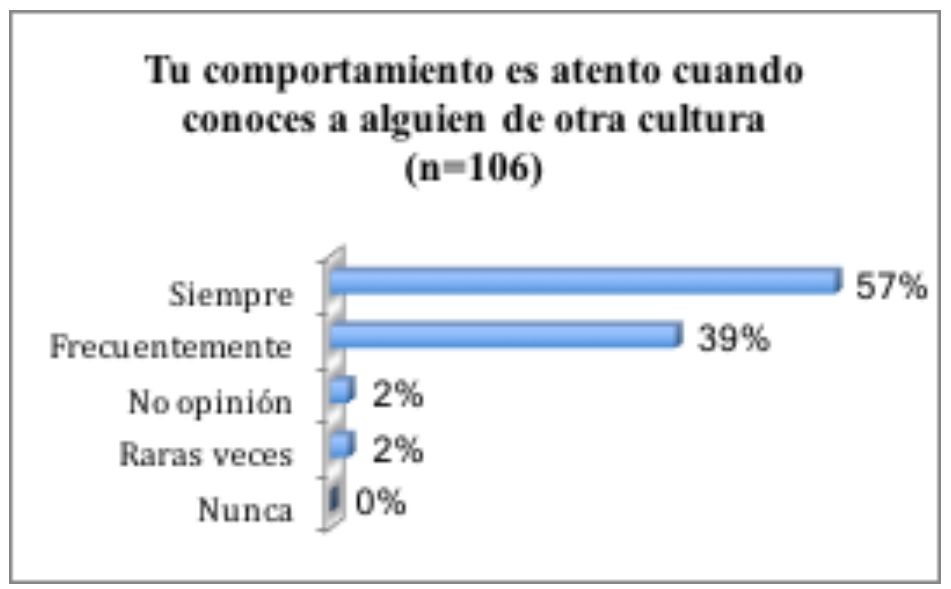

En efecto, $57 \%$ de los estudiantes expone que es siempre respetuoso cuando conoce a alguien de otra cultura y $39 \%$ lo hace frecuentemente. 
Figura 5. Prejuicios hacia otras culturas

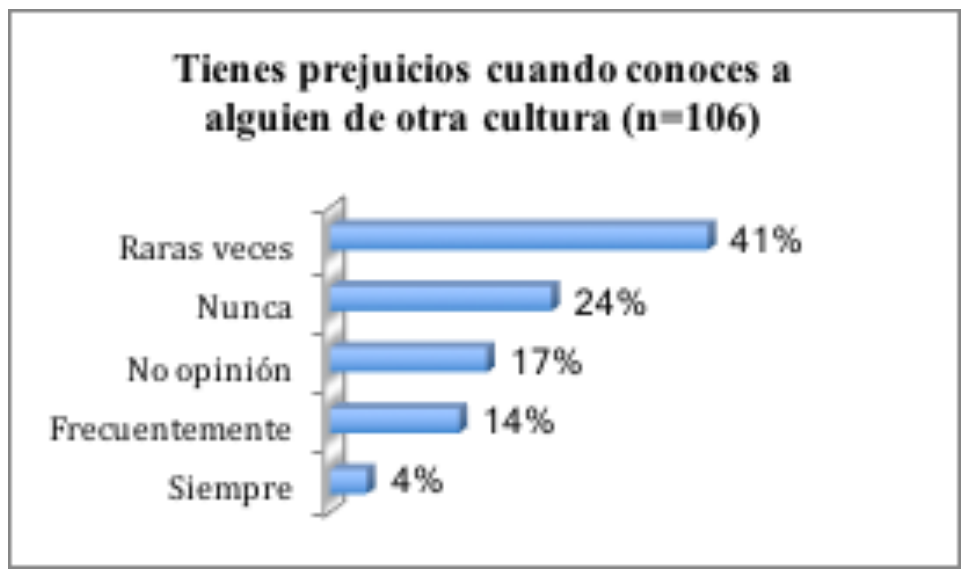

En relación con los prejuicios y, por consiguiente, a su apertura hacia el otro, solamente $14 \%$ dice tener frecuentemente prejuicios y $41 \%$ manifiesta que raras veces tiene prejuicios.

Figura 6. Interés hacia otras culturas

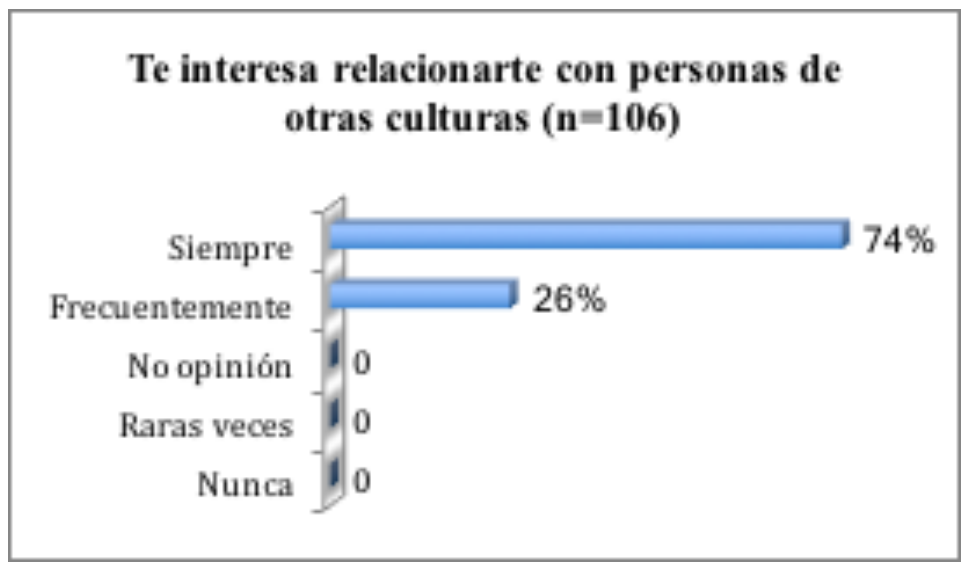

Respecto a la curiosidad, 74\% siempre tiene curiosidad hacia personas de otras culturas, independientemente de su edad, sexo, cultura o condición social, y $26 \%$ contestó que frecuentemente.

En el grupo focal, la mayoría de los participantes manifiesta que este interés hacia otras culturas ha incrementado durante la carrera de Turismo que están cursando. Muchos afirman que tienen curiosidad de saber qué opinan los extranjeros de México, de su cultura y de su gente.

\section{Diálo Dos}


Pasando a la parte de las habilidades internas, se tienen los siguientes resultados:

Figura 7. Adaptación

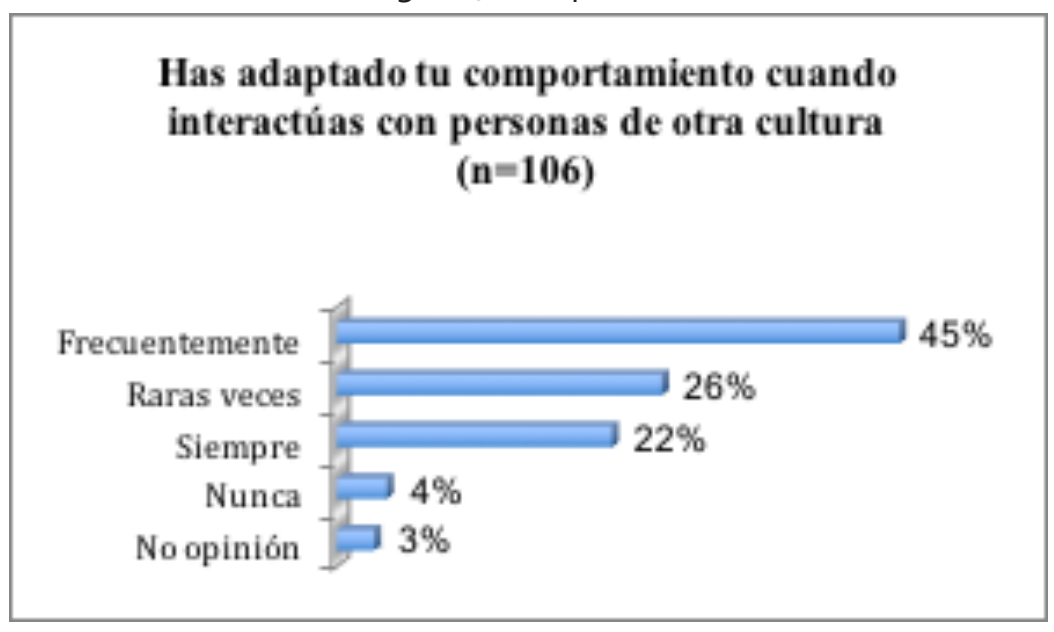

$45 \%$ los estudiantes resultaron ser frecuentemente adaptables y pacientes cuando interactúan con personas de otra cultura y $22 \%$ afirmó que siempre es adaptable y paciente. Solamente $26 \%$ adapta raras veces su comportamiento cuando habla con un extranjero y $4 \%$ no lo hace nunca.

Figura 8. Flexibilidad

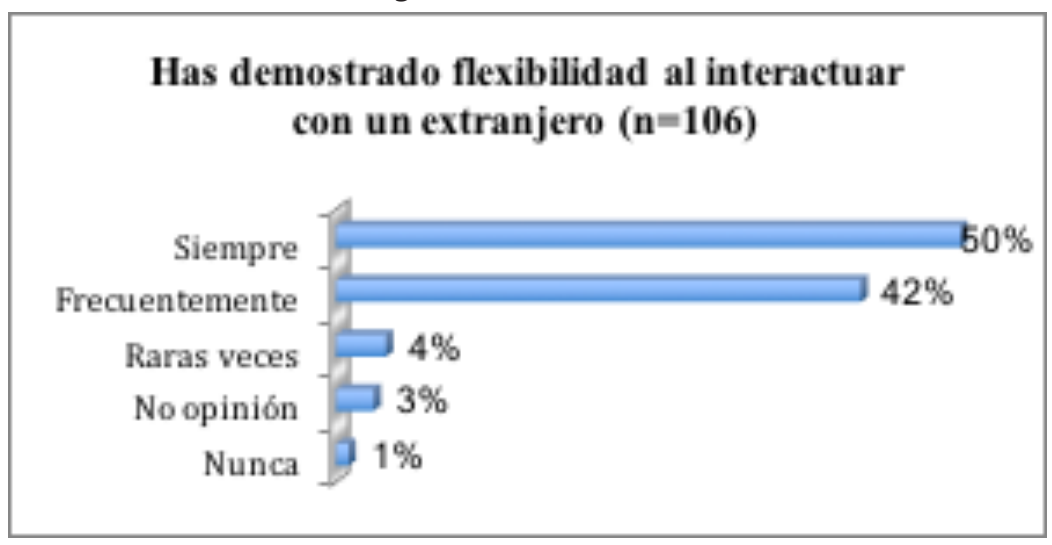

En cuanto a la flexibilidad y tolerancia, $50 \%$ es siempre flexible cuando interactúa con una persona extranjera y $42 \%$ lo es frecuentemente. 
También en relación con etnorrelativismo y suspensión del juicio, según el modelo desarrollado por Bennett (2004), el Develpmental Model of Intercultural Sensitivity (DIMS), los estudiantes se sitúan en el lado del etnorrelativismo, puesto que $57 \%$ dijo que nunca juzga una persona desde el punto de vista de su cultura y $34 \%$ lo hace raras veces. Únicamente $5 \%$ contestó que frecuentemente. $2 \%$ afirma que siempre lo hace y se sitúa en una posición etnocéntrica de Defensa (Bennett, 2004).

Figura 9. Etnocentrismo

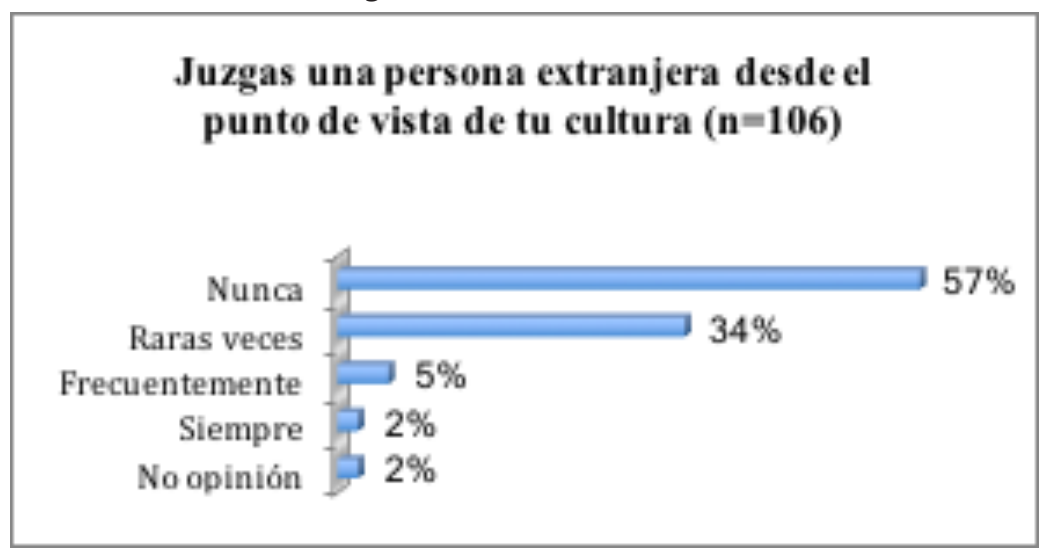

En el grupo focal, los participantes confirmaron las tendencias de las respuestas de la encuesta, sin embargo, sobre los prejuicios emerge que la mayoría de los participantes tiene prejuicios hacia los extranjeros y que los juzgan desde su cultura antes de interactuar con ellos, luego rompen el estereotipo que tenían (o intentan hacerlo) al momento de la interacción.

Figura 10. Entendimiento

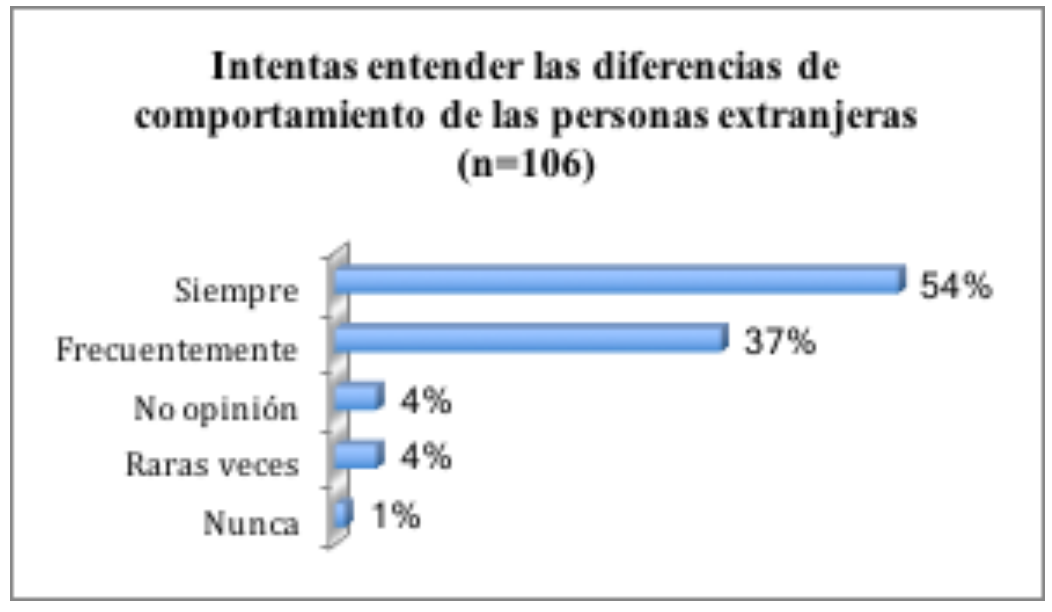

Diálo os 
Por último, los estudiantes demuestran ser empáticos hacia personas de diferentes culturas. 54\% reportó que siempre entiende las diferencias y $37 \%$ que lo hace frecuentemente, como muestra la figura 10.

Empero, en el grupo focal sobresale que los participantes entienden las diferencias comportamentales de un extranjero y las aceptan hasta cierto punto. Algunos de ellos aportaron algunos ejemplos: hasta que no los obliguen a actuar de la misma forma o de una manera que vaya en contra de las costumbres de su cultura.

Se deduce entonces que la gran mayoría de los estudiantes se encuentra en la fase de Aceptación de Bennett (2004), es decir, saben reconciliar las diversidades y similitudes que existen entre la otra cultura y la propia al interactuar con una persona extranjera.

En cambio, en relación con lo que Deardorff (2004) identifica como las habilidades externas, es decir, la capacidad de comunicarse apropiadamente en una situación intercultural, hubo respuestas más variadas. Observando el gráfico que se presenta a continuación (figura 11) solamente $13 \%$ ha tenido frecuentemente malentendidos con personas extranjeras y $39 \%$ raras veces.

Figura 11. Malentendidos

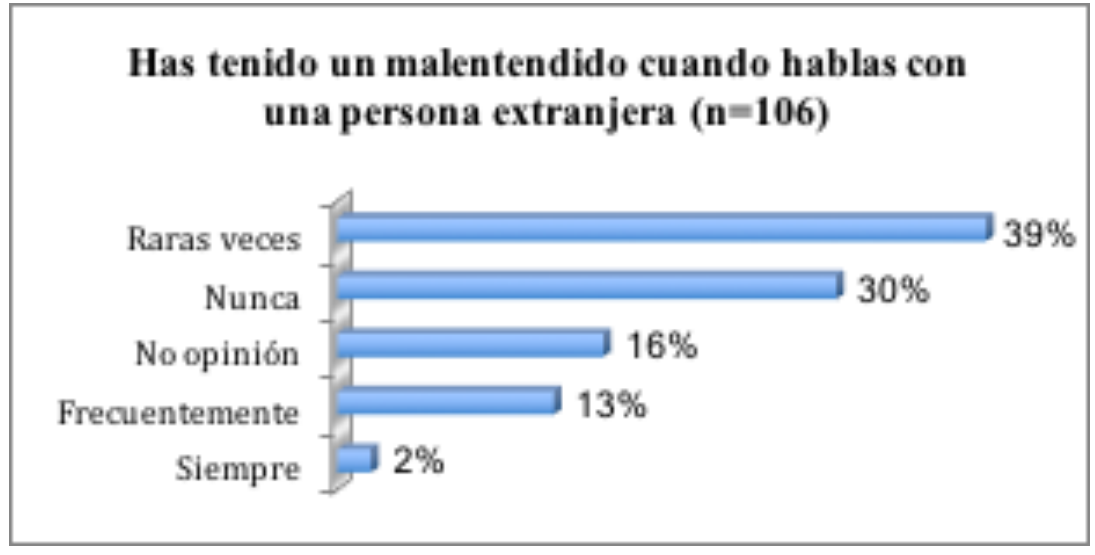


Figura 12. Cambio conductual

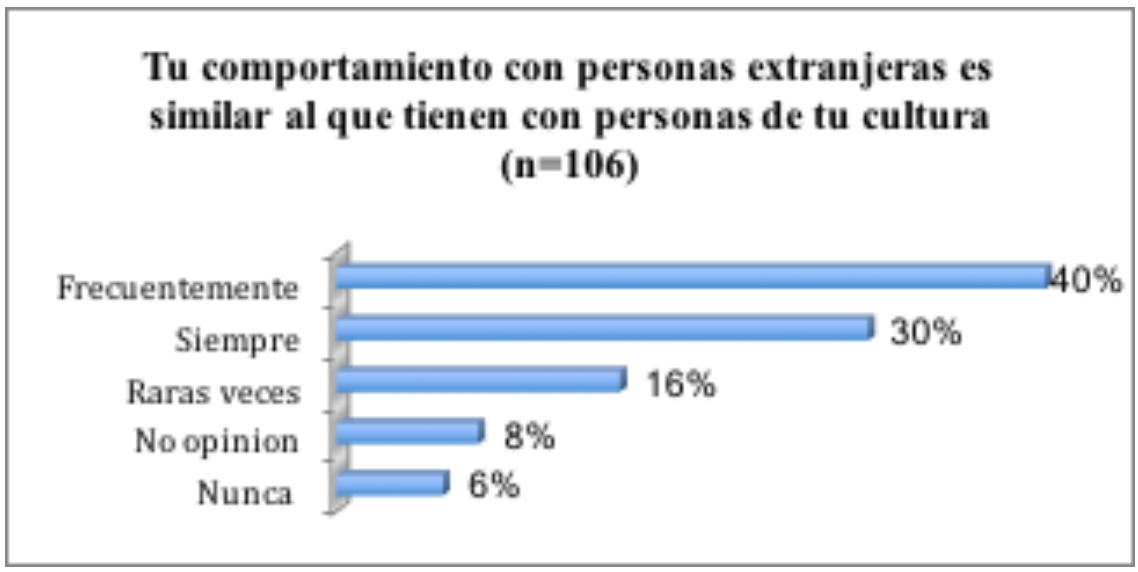

En la figura 12 sobresale que solamente $16 \%$ cambia en raras ocasiones su comportamiento cuando habla con personas extranjeras y $6 \%$ nunca lo hace.

En cambio, resultan interesantes las respuestas que los estudiantes dieron a la pregunta sobre su comportamiento al viajar a un país extranjero (figura 13). 25\% contestó "no opinión" y en el grupo focal la mayoría reportó haber elegido esta opción porque no han viajado al extranjero. Sin embargo, $25 \%$ reportó que nunca cambia su comportamiento y $21 \%$ que raras veces. $20 \%$ declaró que frecuentemente cambia su comportamiento y $9 \%$ siempre lo hace.

Este dato demuestra que los estudiantes están más cercanos al etnocentrismo que al etnorelativismo, porque demuestran no poder integrar la otra cultura en la práctica (Bennett, 2010).

Figura 13. Cambio conductual en el extranjero

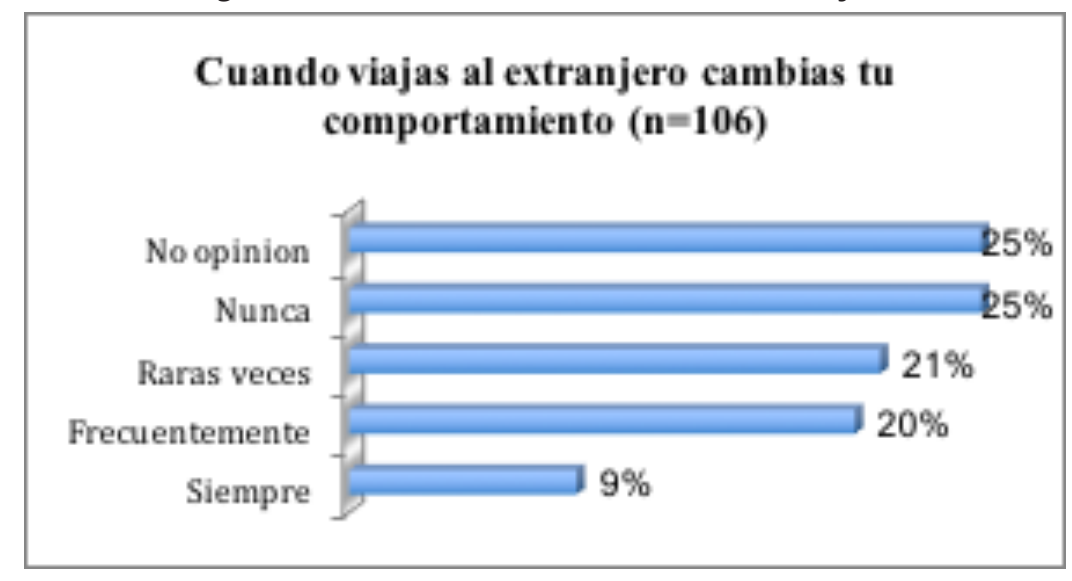

Diálo@os 
Referente a la parte de la encuesta dedicada al conocimiento comunicativo intercultural, es decir, la autoevaluación del conocimiento de la cultura y de la lengua extranjera que estudian, las respuestas evidencian unos hallazgos importantes, como se observa en las figuras de la 14 a la 18.

Figura 14. Conocimiento de tu cultura

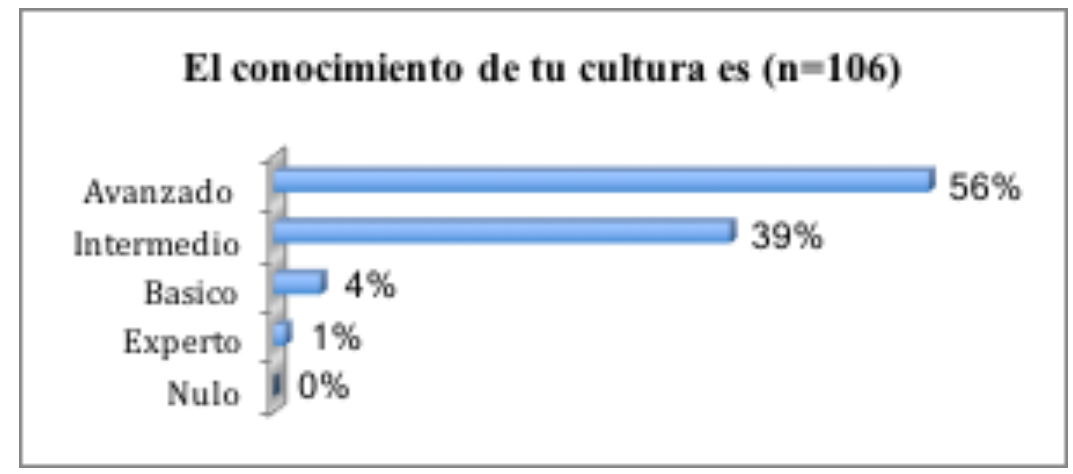

Los estudiantes mencionaron tener un alto grado de conocimiento de su cultura (figura 14), ya que $56 \%$ comenta tener un nivel avanzado y $39 \%$ intermedio.

En el grupo focal, la mayoría de los participantes considera que tiene un conocimiento intermedio de su cultura; aunque la carrera los ha ayudado a ampliar los conocimientos culturales de su país, sienten que les falta conocer más. Manifiestan, con diferentes ejemplos, que México es un país multicultural. Además, agregaron que interactuar con extranjeros fomenta en ellos la curiosidad hacia su propia cultura, que antes no tenían.

Figura 15. Conocimiento cultura extranjera

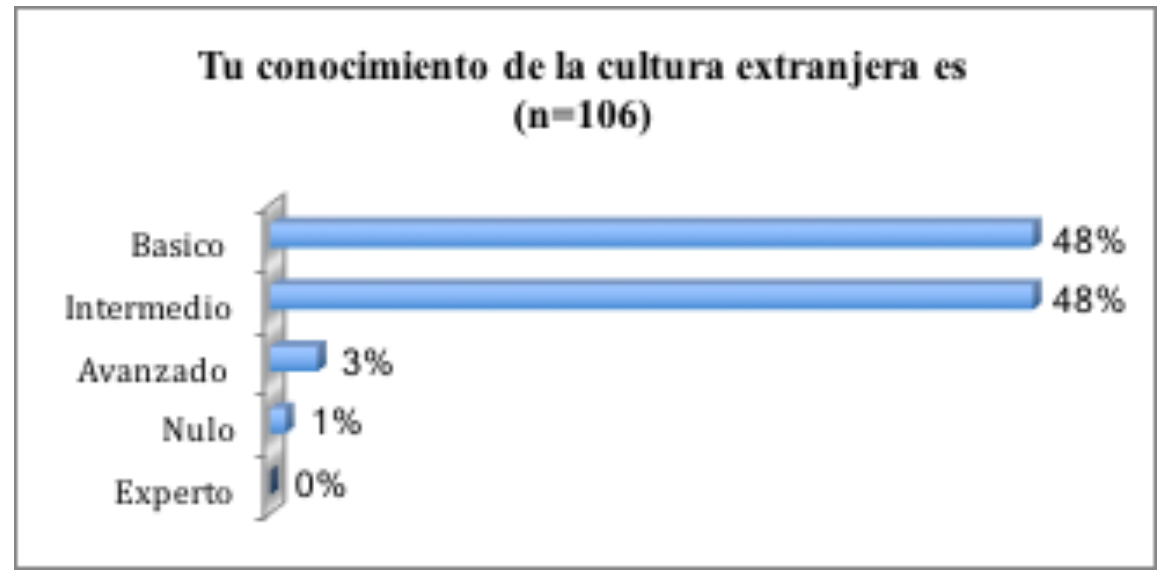


En cambio, se evaluaron a un nivel básico casi la mitad (48\%) respecto al conocimiento de la cultura y de la lengua que están estudiando, otro $48 \%$ declaró tener un nivel intermedio y solamente $3 \%$ manifiesta tener un nivel avanzado (figura 15).

Figura 16. Conocimiento de las normas sociales

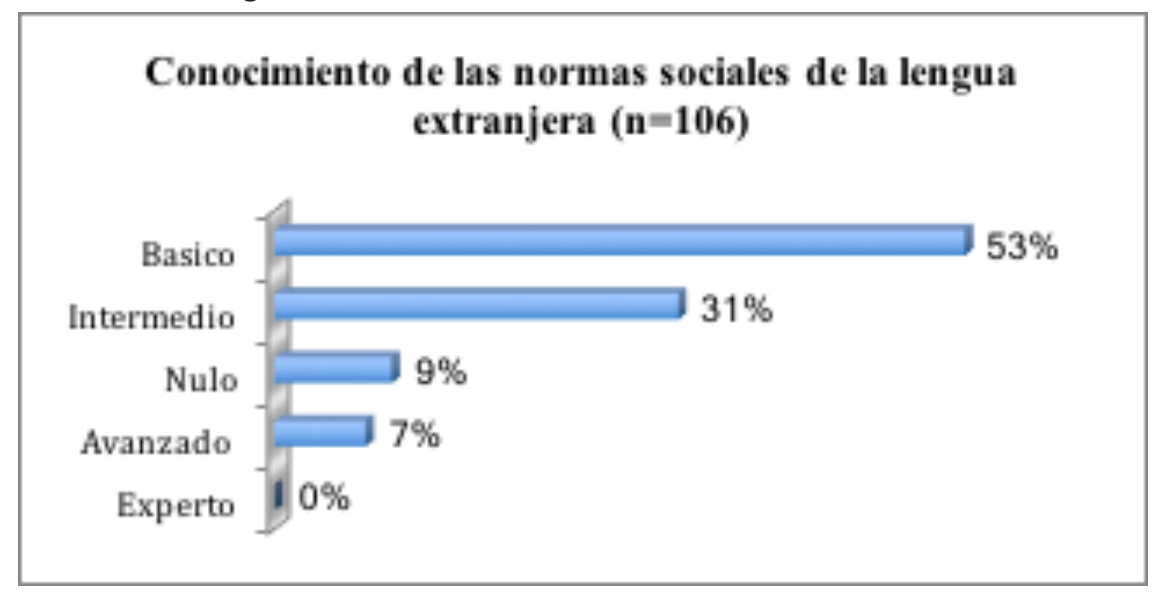

Los resultados anteriores se repiten para el conocimiento de las normas sociales de la lengua extranjera que estudian (figura 16), 53\% declara tener un conocimiento básico, 31\% intermedio y solamente $7 \%$ manifestó tener un nivel avanzado.

Figura 17. Conocimiento de tabúes culturales

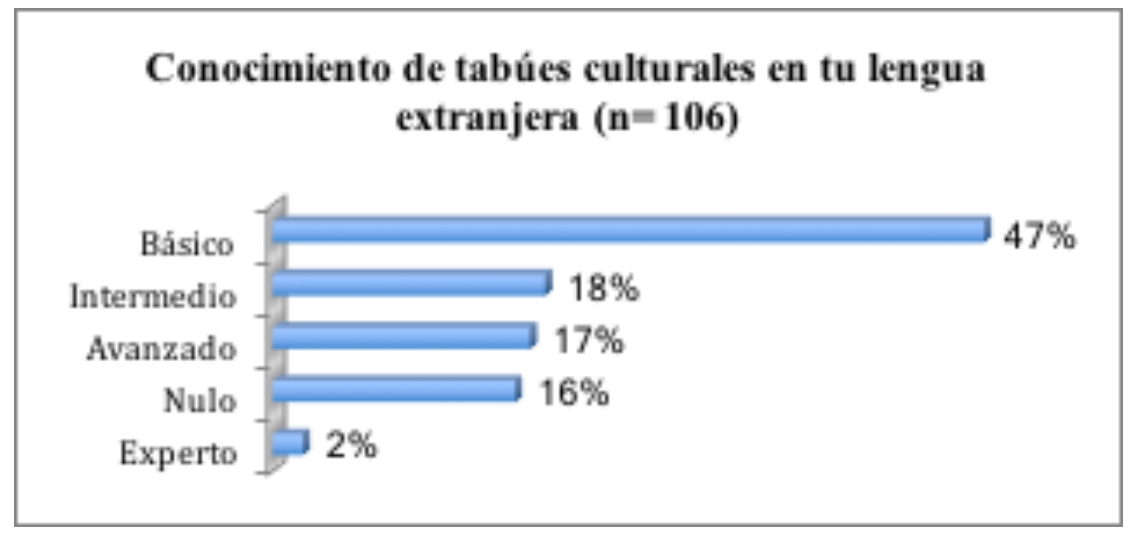

Diálo@os 
Igualmente, para el conocimiento de tabúes culturares de la lengua extranjera (figura 17), $47 \%$ declara tener un conocimiento básico, $18 \%$ intermedio, nulo $16 \%$ y $17 \%$ declaró tener un nivel avanzado.

Figura 18. Conocimiento de la lengua extranjera

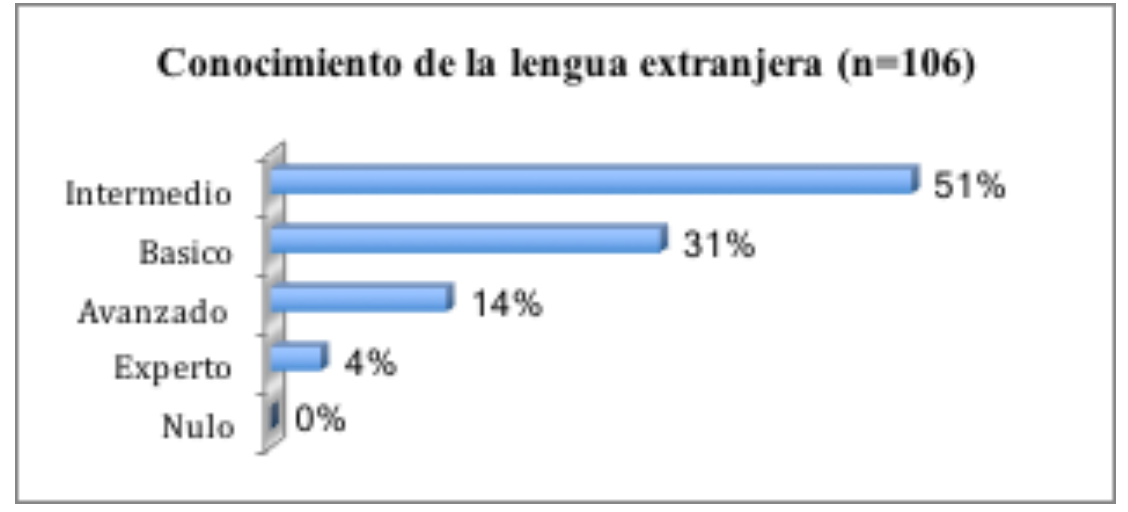

Los resultados varían un poco en cuanto al conocimiento de la lengua extranjera (figura 18), donde los estudiantes se evalúan más alto: $51 \%$ (la mitad) expone que posee un conocimiento intermedio, pero $31 \%$ menciona tener un nivel básico y solamente $14 \%$ declaró colocarse en un nivel avanzado.

En el grupo focal, todos los participantes manifestaron interés por la cultura de la tercera lengua que eligieron y desinterés hacia la cultura de la lengua inglesa. Los estudiantes exponen que son conscientes de la relevancia que el inglés tiene a nivel laboral. Sin embargo, conciben esta lengua únicamente como medio de comunicación, no quieren profundizar aspectos de la cultura estadunidense. La mayoría ha mostrado rechazo hacia esta cultura, los participantes destacan que el desintiéres está relacionado con el hecho de que el inglés es el idioma obligatorio y que los maestros de inglés no hablan de temas culturales en las clases.

Los resultados obtenidos en la tercera y cuarta parte de la encuesta, y en el grupo focal, demuestran que los estudiantes no creen poseer un profundo conocimiento cultural y sociolingüístico de la lengua que estudian, y que al momento de comunicarse con personas de otra cultura no siempre han tenido una comunicación eficaz y sienten que necesitan aprender más sobre estos aspectos de su tercera lengua extranjera (Deardorff, 2004).

Adicionalmente, los estudiantes sugirieron que los cursos de lengua inglesa se enfoquen más a la comunicación y que se integren eventos culturales (como festivales de cine, eventos gastronómicos, etc.) para complementar los cursos de las lenguas extranjeras. Además, pro- 
pusieron que el inglés sea obligatorio para todas las licenciaturas del Centro, dada la posición central que el inglés ocupa en la comunicación económica a nivel mundial.

Desde hace dos décadas, en el proceso de enseñanza y aprendizaje de las lenguas extranjeras se promueve el método comunicativo, que tiene como objetivo que los estudiantes no solamente lleguen a ser entendidos en la lengua extranjera, sino aceptados por el hablante de la otra cultura; lo cual implica desarrollar competencias comunicativas e interculturales.

La competencia comunicativa intercultural es el conjunto del conocimiento de otra cultura y del conocimiento comunicativo (sociolingüístico) de la otra lengua. Si falta uno de los dos componentes, los estudiantes no pueden interactuar de una manera eficaz.

\section{Conclusiones}

Los resultados del estudio informan sobre el estato de las $\mathrm{Cl}$ de los alumnos de la carrera de Turismo, que evalúan positivamente su actitud y habilidades interculturales internas, situándose en la fase de aceptación del DIMS de Bennett (2004).

Sin embargo, analizando la autoevaluación de sus habilidades externas y de los conocimientos interculturales, parece haber una desconexión entre el conocimiento lingüístico-comunicativo de las lenguas extranjeras y el conocimiento sociocultural de las mismas.

Las razones de esta discordancia pueden relacionarse con múltiples factores, por ejemplo: los cursos de lengua extranjera no dedican tiempo suficiente a los aspectos culturales, sociolingüísticos y comunicativos. Incluso, como reportan los participantes del grupo focal, las causas podrían relacionarse con la falta de actividades de internacionalización en casa, que apoyen y profundicen los aspectos culturales de los cursos de idiomas.

En la actualidad es imprescindible que un curso de lengua extranjera se enfoque en el desarrollo de las competencias culturales y comunicativas como objetivo (Fantini, 2005). Esto implica el uso de métodos didácticos creativos que permitan fomentar, recrear y trasformar las culturas, en tres valores básicos: la diversidad cultural, la identidad cultural, y la igualdad en dignidad de todos los individuos que integran la sociedad.

En segundo lugar, se manifiesta la exigencia de implementar estrategias para mejorar la motivación en el estudio de la lengua y de la cultura anglófona. Los participantes en el grupo focal, todos estudiantes de la Licenciatura en Turismo, declararon entender la importancia del conocimiento del inglés, sin embargo, mostraron un total rechazo hacia dicha cultura.

Considerando que el estudio de una lengua y cultura extranjera ofrece diversas oportunidades como: conocer más sobre los otros, reflexionar sobre la cultura propia, moverse de las limitaciones del etnocentrismo para tener perspectivas diferentes (Fantini, 2009). Los estudiantes encuestados tienen hacia la cultura estadunidense una actitud cerrada, etnocéntrica, poco tolerante y flexible; un perfil opuesto a lo que se espera de un futuro turistólogo.

Diálopos 
Finalmente, se descubrió otro dato importante: $25 \%$ de los estudiantes no ha salido al extranjero y no ha participado en un intercambio. El dato revela la exigencia de implementar más y mejores estrategias de internacionalización en casa en la UdeG, que apoyarían en la formación de un egresado de Turismo que piense de una manera global y sustentable, ya que los participantes del grupo focal informan que por varias razones no han podido salir de su país para estudiar en el extranjero.

Se espera que el presente trabajo abra camino para otros estudios sobre las competencias interculturales y la evaluación del impacto de las estrategias de internacionalización en casa dirigidas al desarrollo intercultural de los estudiantes.

Por consiguiente, el estudio deja abiertas algunas interrogantes que hay que investigar a profundidad: ¿Cuáles son las dimensiones de la competencia intercultural que los egresados de la Licenciatura en Turismo deberían poseer? ¿Se están preparando egresados con un perfil de turistólogo global?

\section{Referencias}

Agnew, M.; H. Kahn (2014). Internationalization-at-Home: Grounded Practices to Promote Intercultural, International, and Global Learning. Metropolitan Universities, 25(3), 31-46.

Alsina Valdés y Capote, J.; V. Ampudia Rueda (2009). La internacionalización de la educación superior: Estandarización de criterios para objetos de aprendizaje interactivos. Reencuentro, 54, 111-122.

Altbach, P. G.; J. Knight (2006). Visión panorámica de la internacionalización en la educación superior: Motivaciones y realidades. Perfiles Educativos, 28(112), 13-39.

Altbach, P. G.; L. Reisberg; L. E. Rumbley (eds.) (2009). Trends in Global Higher Education. Tracking an Academic Revolution. París: UNESCO.

Bauman, Z. (2000). Modernidad líquida. El Salvador: Fondo de Cultura Económica.

Beelen, J. y J. Jones (2015). Redefining Internationalization at Home. En A. Curai, A.; L. Matei; R. Pricopie; J. Salmi; P. Scott (eds.). The European Higher Education Area: Between Critical Reflections and Future Policies. Dordrecht: Springer, 67-80.

Bennett, M. J. (2004). Becoming Interculturally Competent. En J. Wurzel (ed.), Toward Multiculturalism: A Reader in Multicultural Education. Newton, MA: Intercultural Resource Corporation, 62-77.

Bennett, M. J. (Febrero, 2010). Creating an Interculturally Competent Campus to Educate Global Citizens. Proceedings of the Universidad 2010 7th International Congress on Higher Education, The University for a Better World. Congreso llevado a cabo en La Habana, Cuba.

Byram, M. (1997). Teaching and Assessing Intercultural Communicative Competence. Clevedon: Multilingual Matters. 
Creswell, J. (2014). Research Design: Qualitative, Quantitative and Mixed Method Approches. California: Sage Publications.

Deardorff, D. K. (2004). In Search of Intercultural Competence. International Educator, 13(2), $13-$ 15.

Deardorff, D. K. (2004). The Identification and Assessment of Intercultural Competence as a Student Outcome of Internationalization at Universities of Higher Education in the United States (Tesis doctoral) North Carolina State University: Raleigh.

Deardorff, D. K. (2011). Assessing Intercultural Competence. New Directions for Institutional Research, 149, 65-79.

De Wit, H. (2011). Globalization and Internationalization of Higher Education. Revista de Universidad y Sociedad del Conocimiento (RUSC), 8(2), 241-248.

De Wit, H.; E. Jones (2014). We Need to Change the Language of Internationalization. University World News the Global Window of Higher Education, Issue (343).

Fantini, A. E. (2000). A Central Concern: Developing Intercultural Competence. SIT Occasional Papers, (1), 25-42.

Fantini, A. E. (2005). Assessing Intercultural Competence: A Research Project of the Federation EIlL. USA: Federation EIL, 1-21.

Fantini, A. E. (2009). Developing Intercultural Competencies: An Educational Imperative for the 21 st Century. Studies in Language and Literature, 28(2), 193-213.

Gregersen-Hermans, J. (2014). The Missing Link in Intercultural Competence Development: The University's Organizational Capability to Deliver. International Higher Education, 78, 8-10.

Griffith, R. L.; L. Wolfeld; B. Armon; J. Rios; O. L. Liu (2016). Assessing Intercultural Competence in Higher Education: Existing Research and Future Directios. Wiley Online Library, 1-44.

Hammer, M. R.; M. J. Bennett y R. Wiseman (2003). Measuring Intercultural Sensitivity: The Intercultural Development Inventory. International Journal of Intercultural Relations, 27, 421-443.

Jones, E. (2014) Graduate Employability and Internationalization of the Curriculum at Home. Internationalization of Higher Education, 78, 6-8.

Knight, J. (2008). Higher Education in Turmoil. The Changing World of Internationalization. Rotterdam: Sense Publishers.

Nilsson, B. (1999 spring). Internationalization at Home: Theory and Praxis. European Association for International Education Forum, 12.

Poder Ejecutivo Federal (2013a). Plan Nacional de Desarrollo 2013-2018. México: PEF-SEP.

Poder Ejecutivo Federal (2013b). Programa Sectorial de Educación 2013-2018. México: PEF-SEP.

Poder Ejecutivo Estatal (2014). Plan Estatal de Desarrollo 2013-2033. México: SEPAF.

Organización para la Cooperación y el Desarrollo Económico (2018). Pisa, Preparing our Youth for an Inclusive and Sustainable World. París: OCDE.

UNESCO (1948). Declaración Universal de los Derechos Humanos. París: UNESCO. 
UNESCO (2013). Intercultural Competences. Conceptual and Operational Framework. París: UNESCO. Universidad de Guadalajara (2014). Plan Institucional de Desarrollo 2014-2030. Guadalajara: Universidad de Guadalajara.

Universidad de Guadalajara (2018). Informe de Matrícula del 2017-2018. Guadalajara: Universidad de Guadalajara.

Universidad de Guadalajara (2019). Informe de Activades 2018. Coordinación General de Cooperación e Internacionalización. Guadalajara: Universidad de Guadalajara.

Universidad de Guadalajara (2019). Numeralia Institucional 2018. Guadalajara: Universidad de Guadalajara. 